\title{
Incidence and risk factors for delirium in older patients with hip fracture
}

Peiyan Ho ${ }^{1}$, MBBS, MRCP, Jagadish Mallya ${ }^{1}$, MBBS, FRCP, Wenqi Mok ${ }^{1}$, BSc, AdvDip, Priscilla Ng ${ }^{1}$, MBBS, MRCP, Su Su ${ }^{1}$, MBBS, MRCP, Antony Premchand ${ }^{2}$, MBBS, MMed, James Hui ${ }^{2}$, MBBS, FRCS, Hui Ng${ }^{1}$, BEng, Stephen Allen ${ }^{3,4}$, MD, FRCP

\begin{abstract}
Introduction. Delirium is a common complication of hip fracture that can be avoided or ameliorated by careful anticipatory case management. We aimed to investigate the incidence and risk factors of delirium in older patients with hip fracture treated in our structured integrated care unit, and to evaluate the impact of delirium on healthcare utilisation.
\end{abstract}

Methods. We retrospectively reviewed records of patients aged $\geq 60$ years and admitted to our unit from December 2014 to September 2018 with low-impact hip fracture. Our unit has implemented a structured integrated care programme based on the NICE guidelines. Primary outcome measure was the incidence of delirium. The diagnosis of delirium was established using the Confusion Assessment Method. Secondary outcome measures included length of hospital stay, readmission within 30 days of discharge, and mortality within 30 days and 1 year.

Results. A total of 1304 patients were included and classified as nondelirium (349 men and 815 women; mean age, 79.2 years) and delirium (49 men and 91 women; mean age, 82.3 years). The overall withinepisode incidence of delirium was thus $10.7 \%$. Independent risk factors for delirium in older patients with hip fractures were age (odds ratio $[O R]=1.028, p=0.02)$, surgical treatment $(O R=2.202, p=0.006)$, dementia $(\mathrm{OR}=2.066, \mathrm{p}=0.001)$, elevated body temperature $(\mathrm{OR}=1.966, \mathrm{p}=0.001)$, urinary tract infection $(\mathrm{OR}=2.431, \mathrm{p}<0.001)$, and acute coronary syndrome $(\mathrm{OR}=4.587, \mathrm{p}<0.001)$. Those with delirium had prolonged hospitalisation of $\geq 10$ days $(\mathrm{OR}=2.033, \mathrm{p}<0.001)$ and higher mortality within 30 days $(\mathrm{OR}=3.408, \mathrm{p}=0.002)$ and 1 year $(\mathrm{OR}=1.894, \mathrm{p}=0.004)$.

Conclusion. The incidence of delirium was low in the present study, compared with most studies. The structured integrated care programme in our unit enables early recognition of delirium for prevention and management of delirium in older patients with hip fracture and might contribute to better outcomes.

Key words: Aged; Delirium; Health care costs; Hip fractures

\section{ORIGINAL ARTICLE}

Department of Geriatric Medicine, Khoo Teck Puat Hospital, Singapore

Department of Orthopaedic Surgery, Khoo Teck Puat Hospital, Singapore

3 Department of Medicine and Geriatrics, Royal Bournemouth Hospital, UK

4 Centre for Postgraduate Medical Research and Education, Bournemouth University, UK

\section{INTRODUCTION}

The population of Singapore is expected to grow from 5.7 million to 6.6 million between 2017 and $2050,{ }^{1}$ by which time about $40 \%$ of Singaporeans are expected to be aged $>60$ years. ${ }^{2}$ Hip fracture is likely to be a major public health issue for this increasingly ageing population. In economically advanced countries, the lifetime risk of hip fracture is typically about $11 \%$ for men and $23 \%$ for women, with almost half of all 
hip fractures occurring in those aged $\geq 80$ years. ${ }^{3}$ Hip fracture in older people results in an increased risk of mortality, impaired quality of life, and persistent physical morbidity. In Singapore, in 2013, the 1-year mortality rate after a fragility hip fracture was approximately $20 \%$ to $27 \%$. Furthermore, $20 \%$ of such patients remained partially or fully dependent, around $40 \%$ had reduced mobility, and an increasing proportion lived in an institutionalised home. ${ }^{4,5}$

In the United States, $48 \%$ of patients with hip fracture aged $\geq 65$ years had a degree of delirium before, during, or after surgery. ${ }^{6}$ Delirium is a severe neuropsychiatric syndrome that is common and serious in older patients with hip fracture. It is often under-recognised and undertreated, and can occur at any time during the course of hip fracture episode. ${ }^{7,8}$ Delirium can unravel a cascade of adverse outcomes that have significant implications for patients and their families, with a substantial impact on healthcare utilisation and costs. Delirium causes prolonged hospitalisation, ${ }^{9}$ delayed rehabilitation efforts, ${ }^{10,11}$ poorer functional outcomes and cognitive function, ${ }^{10}$ increased risk of nursing home placement, ${ }^{12,13}$ and increased mortality after hip fracture. ${ }^{13,14}$ Delirium is associated with high rates of mortality both in hospital and after discharge, especially for those who underwent surgery. ${ }^{15-17}$ Delirium is also associated with the development of dementia, ${ }^{3}$ although it is unclear whether delirium is a marker of undetected dementia or whether delirium contributes to the development of dementia, or both. ${ }^{13}$

Although the aetiology of delirium in older patients with hip fracture is usually multifactorial, reduced cognitive reserve appears to be an important predisposition. According to the National Institute for Health and Care Excellence (NICE), ${ }^{18}$ the five major risk factors associated with postoperative delirium are age $>65$ years, chronic cognitive decline or dementia, poor vision or hearing, severe comorbid illness (affecting activity of daily living), and the presence of infection. Of these, age is the most significant predictor. ${ }^{18-21}$

A review of 25 studies categorised risk factors of delirium into predisposing and precipitating factors. The former include age, male sex, cognitive impairment, functional impairment, sedentary lifestyle, major comorbidity such as cardiovascular disease, congestive cardiac failure, depression, and polypharmacy (>3 prescribed drugs). The latter include laboratory abnormalities such as anaemia and disturbed electrolytes, depression, and drugs, particularly opioids and anticholinergics. ${ }^{21}$

Other studies have suggested associations between delirium and malnutrition, sensory (vision and hearing) impairment, history of cerebrovascular disease, endocrine disease, prolonged waiting time for operation, type of fracture, type of anaesthesia, inadequate analgesia, elevated temperature, pneumonia, and urinary tract infection; however, none has shown clear single associations. In clinical practice, these factors appear to be contributary to multifactorial delirium..$^{21-31}$

Therefore, a better understanding of these factors is useful in attempts to identify patients at high risk of developing delirium and hence devising effective preventive and management strategies.

The present study aimed to determine the incidence and risk factors of delirium in the Geriatric Hip Fracture Unit at Khoo Teck Puat Hospital, Singapore, where a structured integrated care programme was developed and implemented in 2014 using the NICE guidelines. We also aimed to evaluate the impact of delirium on healthcare utilisation as measured by length of hospital stay, readmission to hospital within 30 days of discharge, and mortality within 30 days and 1 year.

\section{METHODS}

Approval for the study was obtained from the Institutional Ethics Review Board of Singapore (reference: 2015/00661). We retrospectively reviewed a prospectively collected database that comprise all patients who were admitted to the Geriatric Hip Fracture Unit at Khoo Teck Puat Hospital, Singapore from December 2014 to September 2018 for treatment of hip fracture. The inclusion criteria were patients aged $\geq 60$ years with a principal diagnosis of accidental low-impact hip fracture (neck of femur, inter-trochanteric fracture or subtrochanteric fracture within $5 \mathrm{~cm}$ of the lesser trochanter). Exclusion criteria were newly diagnosed acute stroke, pathological hip fracture, high-impact hip fracture, or multiple lowerlimb fractures.

The structured integrated care programme in our 
unit included admission within 4 hours to a general ward from the emergency department, surgery within 4 hours of being ready for an operation, early delirium screening, active early optimisation of comorbidities by collaboration with multiple specialties including geriatric medicine, anaesthesia, and, if necessary, with cardiology and other medical specialties. From shortly after admission, corrective attention was given to nutrition, fluids and electrolytes, pain management, urinary tract infection prevention, venous thromboembolism prevention (with subcutaneous low-molecular-weight heparin unless contra-indicated), rehabilitation as early as possible, and active prevention of postoperative complications (if surgery was performed).

The baseline clinical characteristics collected recorded were: age, sex, ethnicity, comorbidities, Charlson comorbidity index, abbreviated mental test (AMT) score, type of fracture and the management options (surgical vs conservative), and the time taken for transfer from the emergency department to a general ward. Clinical data were extracted in patients who developed anaemia requiring blood transfusion, elevated body temperature, presence of urinary tract infection, hospital-acquired pneumonia, wound- or catheter-related infection, deep vein thrombosis, pulmonary embolism, acute cerebrovascular accident, and acute coronary events.

The diagnosis of delirium was established using the Confusion Assessment Method, which provides a standardised evidence-based tool to identify and recognise delirium quickly, effectively, and accurately in both clinical and research settings. ${ }^{32}$ As part of the structure integrated care programme, the Confusion Assessment Method was initiated in the emergency department and continued daily until postoperative day 4 (if the patient underwent surgery) by a trained geriatric nurse and geriatricians, respectively. It takes account of (1) acute onset and/or fluctuation, (2) inattention, (3) disorganised thinking, and (4) altered level of consciousness. The diagnosis of delirium requires the presence of features 1 and 2 and either 3 or 4 . The secondary outcomes measured included length of hospital stay, readmission within 30 days, and mortality within 30 days and 1 year.

Statistical analysis was performed using SPSS (Windows version 22.0; IBM Corp, Armonk $[\mathrm{NY}]$, US). Continuous data were analysed by an independent samples t-test. Categorical variables were described as percentages and analysed by either the Chi-squared test or Fisher's exact test, depending on the sample size. Univariate logistic analysis was used to identify the risk factors associated with delirium in older patients with hip fracture. The variables identified as significant, with the exception of low AMT score, were subsequently included in a stepwise multivariate logistic analysis to identify independent predictors of delirium. A p value of $<0.05$ was considered statistically significant. Low AMT score was not included in the multivariate logistic analysis because a large proportion of AMT data were missing (221 patients, 16.9\%).

\section{RESULTS}

A total of 1304 patients were included from December 2014 to September 2018. The non-delirium group comprised 1164 patients (349 men and 815 women; mean age, $79.2 \pm 8.8$ years) and the delirium group 140 patients (49 men and 91 women; mean age, $82.3 \pm 8.1$ years). The overall within-episode incidence of delirium was thus $10.7 \%$.

Univariate logistic analysis revealed that delirium in older patients with hip fracture was associated with age (odds ratio $[\mathrm{OR}]=1.041, \mathrm{p}<0.001$ ), Charlson comorbidity index $(\mathrm{OR}=1.123, \mathrm{p}=0.009)$, chronic obstructive pulmonary disease $(\mathrm{OR}=5.076, \mathrm{p}=0.027)$, ischaemic heart disease $(\mathrm{OR}=1.865, \mathrm{p}=0.005)$, chronic kidney failure $(\mathrm{OR}=2.684, \mathrm{p}=0.001)$, thyroid disorders $(\mathrm{OR}=8.42, \mathrm{p}=0.034)$, dementia $(\mathrm{OR}=2.283$, $\mathrm{p}<0.001)$, low AMT score of $<8(\mathrm{OR}=2.577, \mathrm{p}<0.001)$, elevated body temperature $(\mathrm{OR}=2.417, \mathrm{p}<0.001)$, urinary tract infection $(\mathrm{OR}=3.06, \mathrm{p}<0.001)$, hospitalacquired pneumonia $(\mathrm{OR}=3.358, \mathrm{p}<0.001)$, and acute coronary syndrome $(\mathrm{OR}=5.09, \mathrm{p}<0.001)$. In addition, delirium was associated with prolonged hospitalisation of $\geq 10$ days $(\mathrm{OR}=2.033, \mathrm{p}<0.001)$, and mortality within 30 days $(\mathrm{OR}=3.408, \mathrm{p}=0.002)$ and 1 year $(\mathrm{OR}=1.894, \mathrm{p}=0.004)$ [Table 1].

Multivariate analysis showed that independent risk factors for delirium in older patients with hip fractures were age $(\mathrm{OR}=1.028, \mathrm{p}=0.02)$, surgical treatment $(\mathrm{OR}=2.202, \mathrm{p}=0.006)$, dementia $(\mathrm{OR}=2.066, \mathrm{p}=0.001)$, elevated body temperature $(\mathrm{OR}=1.966, \mathrm{p}=0.001)$, urinary tract infection $(\mathrm{OR}=2.431, \mathrm{p}<0.001)$, and acute coronary syndrome $(\mathrm{OR}=4.587, \mathrm{p}<0.001)$ [Table 2]. 
TABLE 1

Patient characteristics and outcome of the delirium and non-delirium groups and univariate analysis for risk factors of delirium in older patients with hip fracture

\begin{tabular}{|c|c|c|c|c|c|}
\hline Variables & $\begin{array}{l}\text { Delirium group } \\
\qquad(n=140)^{*}\end{array}$ & $\begin{array}{l}\text { Non-delirium } \\
\text { group } \\
(n=1164)^{\star}\end{array}$ & $\mathrm{p}$ Value & $\begin{array}{l}\text { Unadjusted odds ratio } \\
(95 \% \text { confidence interval } \\
\text { for exp (B)) }\end{array}$ & $\mathrm{p}$ Value \\
\hline Age, y & $82.3 \pm 8.1$ & $79.2 \pm 8.8$ & $<0.001$ & $1.041(1.02-1.063)$ & $<0.001$ \\
\hline Age group, y & & & $<0.001$ & & \\
\hline $60-69$ & $11(5.6)$ & $187(94.4)$ & & 1 & \\
\hline $70-79$ & $37(8.6)$ & $393(91.4)$ & & $1.601(0.799-3.208)$ & 0.185 \\
\hline $80-89$ & $64(12.5)$ & $446(87.5)$ & & $2.439(1.258-4.73)$ & 0.008 \\
\hline$\geq 90$ & $28(16.9)$ & $138(83.1)$ & & $3.449(1.66-7.167)$ & 0.001 \\
\hline Sex & & & 0.223 & & \\
\hline Male & 49 (12.3) & $349(87.7)$ & & $1.257(0.869-1.1819)$ & 0.224 \\
\hline Female & $91(10.0)$ & $815(90.0)$ & & 1 & \\
\hline Ethnicity & & & 0.296 & & \\
\hline Chinese & 106 (10.3) & $921(89.7)$ & & 1 & \\
\hline Malay & $26(14.5)$ & $153(85.5)$ & & 1.477 (0.93-2.343) & 0.098 \\
\hline Indian & $6(8.7)$ & $63(91.3)$ & & $0.827(0.35-1.958)$ & 0.667 \\
\hline Others & $2(6.9)$ & $28(93.1)$ & & $0.644(0.151-2.745)$ & 0.551 \\
\hline Type of fracture & & & 0.506 & & \\
\hline Intertrochanteric & $69(11.4)$ & $538(88.6)$ & & 1 & \\
\hline Neck of femur & $66(9.9)$ & $598(90.1)$ & & $0.861(0.602-1.23)$ & 0.41 \\
\hline Subtrochanteric & $5(15.2)$ & $28(84.8)$ & & $1.392(0.52-3.725)$ & 0.51 \\
\hline Management & & & 0.144 & & \\
\hline Surgery & $119(11.4)$ & $929(88.6)$ & & $1.433(0.882-2.329)$ & 0.146 \\
\hline Non surgery & $21(8.2)$ & 235 (91.8) & & 1 & \\
\hline Charlson comorbidity index & $5.76 \pm 1.67$ & $5.33 \pm 1.83$ & 0.009 & $1.123(1.029-1.226)$ & 0.009 \\
\hline \multicolumn{6}{|l|}{ Comorbidities } \\
\hline Hypertension & $98(10.9)$ & $804(89.1)$ & 0.822 & $1.045(0.713-1.531)$ & 0.822 \\
\hline Hyperlipidaemia & $72(11.4)$ & $562(88.6)$ & 0.482 & $1.134(0.799-1.611)$ & 0.482 \\
\hline Diabetes mellitus & $42(9.7)$ & $392(90.3)$ & 0.383 & $0.844(0.576-1.236)$ & 0.383 \\
\hline Asthma & $7(15.2)$ & $39(84.8)$ & 0.318 & $1.518(0.666-3.462)$ & 0.321 \\
\hline Chronic obstructive pulmonary disease & $3(37.5)$ & $5(62.5)$ & 0.014 & $5.076(1.2-21.472)$ & 0.027 \\
\hline Ischaemic heart disease & $31(16.8)$ & $154(83.2)$ & 0.004 & $1.865(1.209-2.877)$ & 0.005 \\
\hline Chronic heart failure & $1(7.7)$ & $12(92.3)$ & 0.722 & $0.691(0.089-5.352)$ & 0.723 \\
\hline Chronic kidney failure & $17(23.0)$ & $57(77.0)$ & $<0.001$ & $2.684(1.514-4.76)$ & 0.001 \\
\hline End stage renal failure & 0 & $3(100)$ & 0.548 & & \\
\hline Liver cirrhosis & $1(50.0)$ & $1(50.0)$ & 0.073 & $8.367(0.52-134.514)$ & 0.134 \\
\hline Anaemia & $16(11.0)$ & $130(89.0)$ & 0.927 & $1.026(0.591-1.782)$ & 0.927 \\
\hline Thyroid disorder & $2(50.0)$ & $2(50.0)$ & 0.011 & $8.42(1.177-60.252)$ & 0.034 \\
\hline Stroke & $10(8.8)$ & $104(91.2)$ & 0.478 & $0.784(0.4-1.538)$ & 0.479 \\
\hline Parkinsonism & 2 (33.3) & $4(66.7)$ & 0.073 & $4.23(0.763-23.157)$ & 0.099 \\
\hline Malignancy & 0 & $1(100)$ & 0.729 & & \\
\hline Dementia & $45(18.4)$ & $200(81.6)$ & $<0.001$ & $2.283(1.552-3.359)$ & $<0.001$ \\
\hline Abbreviated mental test score & & & $<0.001$ & & \\
\hline$<8$ & $84(14.7)$ & $488(85.3)$ & & $2.577(1.682-3.946)$ & $<0.001$ \\
\hline$\geq 8$ & $32(6.3)$ & $479(93.7)$ & & 1 & \\
\hline
\end{tabular}

* Data are presented No. (\%) of cases or mean \pm standard deviation 
Ho et al

TABLE 1 (cont'd)

\begin{tabular}{|c|c|c|c|c|c|}
\hline Variables & $\begin{array}{l}\text { Delirium group } \\
\qquad(n=140)^{*}\end{array}$ & $\begin{array}{l}\text { Non-delirium } \\
\text { group } \\
(n=1164)^{\star}\end{array}$ & $\mathrm{p}$ Value & $\begin{array}{l}\text { Unadjusted odds ratio } \\
(95 \% \text { confidence interval } \\
\text { for exp (B)) }\end{array}$ & $\mathrm{p}$ Value \\
\hline Door to admission & & & 0.471 & & \\
\hline$\leq 4$ hours & $51(11.7)$ & $385(88.3)$ & & 1 & \\
\hline$>4$ hours & $88(10.4)$ & 760 (89.6) & & $0.874(0.606-1.26)$ & 0.471 \\
\hline \multicolumn{6}{|l|}{ Complication } \\
\hline Anaemia requiring transfusion & $79(12.1)$ & $573(87.9)$ & 0.107 & $1.336(0.938-1.902)$ & 0.108 \\
\hline Elevated body temperature & $89(15.4)$ & $488(84.6)$ & $<0.001$ & $2.417(1.681-3.477)$ & $<0.001$ \\
\hline Urinary tract infection & $42(22.7)$ & $143(77.3)$ & $<0.001$ & $3.06(2.048-4.572)$ & $<0.001$ \\
\hline Hospital-acquired pneumonia & $19(26.8)$ & $52(73.2)$ & $<0.001$ & $3.358(1.922-5.866)$ & $<0.001$ \\
\hline Wound infection & $4(23.5)$ & $13(76.5)$ & 0.086 & 2.604 (0.837-8.099) & 0.098 \\
\hline Catheter-related infection & 0 & $3(100)$ & 0.548 & & \\
\hline Acute coronary syndrome & $21(35.0)$ & $39(65.0)$ & $<0.001$ & $5.09(2.899-8.94)$ & $<0.001$ \\
\hline Pressure ulcer & 1 (33.3) & $2(66.7)$ & 0.206 & $4.18(0.377-46.394)$ & 0.244 \\
\hline Deep vein thrombosis & $3(15.0)$ & $17(85.0)$ & 0.535 & $1.477(0.428-5.106)$ & 0.537 \\
\hline Pulmonary embolism & 0 & $11(100)$ & 0.248 & & \\
\hline Stroke & $1(16.7)$ & 5 (83.3) & 0.637 & $1.668(0.193-14.377)$ & 0.642 \\
\hline Length of stay, d & $15.1 \pm 11.6$ & $12.3 \pm 8.4$ & 0.005 & $1.027(1.011-1.042)$ & 0.001 \\
\hline$<10$ & $53(7.6)$ & $645(92.4)$ & $<0.001$ & 1 & \\
\hline$\geq 10$ & $87(14.3)$ & $520(85.7)$ & & $2.033(1.418-2.915)$ & $<0.001$ \\
\hline Readmission within 30 days & $15(13.4)$ & $97(86.6)$ & 0.342 & $1.32(0.743-2.345)$ & 0.344 \\
\hline Mortality within 30 days & $9(28.1)$ & $23(71.9)$ & 0.001 & $3.408(1.544-7.521)$ & 0.002 \\
\hline Mortality within 1 year & 31 (16.9) & $152(83.1)$ & 0.003 & $1.894(1.227-2.922)$ & 0.004 \\
\hline
\end{tabular}

TABLE 2

Multivariate analysis for independent risk factors of delirium in older patients with hip fracture

\begin{tabular}{lcc}
\hline Variable & $\begin{array}{c}\text { Unadjusted odds ratio } \\
(95 \% \text { confidence interval } \\
\text { for exp (B)) }\end{array}$ & p Value \\
\hline Age & $1.028(1.004-1.052)$ & 0.02 \\
Sex & $1.390(0.922-2.097)$ & 0.116 \\
Surgical treatment & $2.202(1.254-3.865)$ & 0.006 \\
Charlson morbidity index & $1.013(0.896-1.145)$ & 0.837 \\
Ischaemic heart disease & $1.569(0.957-2.573)$ & 0.074 \\
Chronic obstructive pulmonary disease & $4.480(0.931-21.560)$ & 0.061 \\
Chronic kidney disease & $1.724(0.883-3.366)$ & 0.111 \\
Thyroid disorder & $6.472(0.829-50.514)$ & 0.075 \\
Dementia & $2.066(1.335-3.198)$ & 0.001 \\
Elevated body temperature & $1.966(1.314-2.942)$ & 0.001 \\
Anaemia requiring transfusion & $0.953(0.643-1.413)$ & 0.812 \\
Urinary tract infection & $2.431(1.560-3.790)$ & $<0.001$ \\
Hospital-acquired pneumonia & $1.802(0.968-3.356)$ & 0.063 \\
Acute coronary syndrome & $4.587(2.473-8.508)$ & $<0.001$ \\
\hline
\end{tabular}




\section{DISCUSSION}

Delirium is an important complication of hip fractures in older patients and has considerable implications for healthcare utilisation, care costs, and mortality risk. The incidence of delirium in our Geriatric Hip Fracture Unit was $10.7 \%$, which is substantially lower than the $13 \%$ to $62 \%$ reported by most other studies. ${ }^{14,33-35}$ Although some of this variation is likely to be due to differences in case mix and definitions, we contend that our low delirium incidence might in part be due to the structured integrated care programme, with early detection and amelioration of risk factors, timely optimisation of patients' physiological status, and application of the NICE delirium guideline. This is consistent with the established evidence that comprehensive geriatric assessment and care reduces the incidence of perioperative delirium across a range of surgical conditions, as demonstrated by meta-analysis of randomised controlled trials. ${ }^{14,33,34}$ The low incidence of delirium in our unit could also have been partly due to the use of the Confusion Assessment Method, which can underdiagnose mild hypoactive delirium. ${ }^{32}$ Our study had neither a parallel nor a preceding control group for comparison of the delirium incidence, so caution is needed when ascribing the low incidence to the structured integrated care. Nevertheless, anecdotal evidence from clinicians supported our interpretation of the benefit of the structured integrated care programme.

There is no high-grade evidence of benefit from specific treatments for established delirium. Therefore, identifying and correcting the risk factors for delirium are the most effective means to reduce the incidence of delirium. This concords with the finding that in the general geriatric population, 30\% to $40 \%$ of the delirium episodes could be prevented by better management of the risk factors. ${ }^{34}$

In the present study, independent risk factors for delirium in older patients with hip fracture were age $>80$ years, surgical treatment, dementia, elevated body temperature, and presence of urinary tract infection and acute coronary syndrome. This concords with other studies in which advanced age was consistently an independent risk factor for delirium in older patients with hip fracture, and the risk rises incrementally with increasing age. ${ }^{18-20,27}$ Similarly, our study established that age was not only an independent risk factor for delirium but also that the incidence of delirium in patients aged 80-89 years $(\mathrm{OR}=2.439,95 \% \mathrm{CI}=1.258-4.73, \mathrm{p}=0.008)$ and $>90$ years $(\mathrm{OR}=3.449,95 \% \mathrm{CI}=1.66-7.167, \mathrm{p}<0.001)$ was higher than that in patients aged $<80$ years. Age is confirmed as the major non-modifiable risk factor for delirium in patients with hip fracture.

Older patients are more susceptible to delirium because of the association between ageing and depleted physiological reserves leading to impaired compensatory capability to adjust to the physical stress of surgery. Older patients generally also have significant neurovascular risk factors, higher white matter vascular damage, and less cognitive reserve; all of which predispose them to a higher risk for cognitive complications in physically stressful circumstances such as hip fracture. ${ }^{33-35}$

The other main non-modifiable risk factor is dementia. Patients with dementia have greatly reduced cognitive reserves as a result of structural alteration and neurotransmitter dysfunction. They frequently have other comorbidities, functional dependency, and poor nutritional state. ${ }^{33}$ In our study, patients with dementia were $>2$ times more likely to develop delirium than patients with normal cognition. The increased risk of delirium in dementia patients is consistent with other studies, and confirms it as a major risk factor for delirium in older patients with hip fracture. ${ }^{21}$

In older patients with hip fracture, those treated operatively were more susceptible to the development of delirium than those managed conservatively. General anaesthesia and surgical trauma have been shown to cause disturbances to a wide variety of neurotransmitters systems and that is the most likely substrate for their proneness to delirium. Our study demonstrated that patients treated surgically were $>2$ times more likely to develop delirium than those treated conservatively.

Elevated body temperature and the presence of urinary tract infection were independent risk factors of delirium in our older patients with hip fracture. These findings concorded with the NICE delirium clinical guideline, which highlighted presence of infection as one of the major risk factors for delirium. There is increasing evidence to suggest that trauma, infection, and surgery can lead to increased 
production of proinflammatory cytokines, ${ }^{30}$ which can induce delirium in susceptible individuals. ${ }^{31}$ High levels of cortisol associated with acute stress might be a factor; patients with postoperative delirium were found to have high cortisol levels after surgery. ${ }^{36}$ The physiological feedback regulation of cortisol might be impaired in older adults resulting in higher levels of baseline cortisol and thereby predisposing them to delirium, although a causative relationship has not been confirmed. A similar mechanism might be at work in patients with hip fracture with acute coronary syndrome who are likewise prone to delirium. Acute coronary syndrome has been reported to be strongly independently associated with delirium. . $^{34,35}$ A full discussion of the biochemical mechanisms of delirium are outside the scope of this paper.

These findings of our study have practical implications for management of older patients with hip fracture during hospitalisation. The benefit of the structured integrated care indicates that patients at high risk should be monitored closely and consistently for early signs of delirium. Delirium in our sample was associated with increased length of hospital stay and increased mortality within 30 days and 1 year after hip fracture. Delirium inevitably has a profound impact on healthcare utilisation. With the rising proportion of the population at risk of fragility hip fracture, the implications of delirium are substantial from clinical and health services perspectives.

Our study has some limitations. First, there was no clear record of when in the episode the delirium was detected. It was unknown whether it was pre-, peri- or post-operative. There was also no record of the severity or subtype of delirium to help to refine the approach to prevent and manage delirium in older patients with hip fracture. Second, the history of cognitive impairment or dementia was evaluated using medical notes. No distinction was made between mild, moderate, and severe cognitive impairment. In addition, dementia often became apparent for the first time at admission; this may have underestimated the number of patients with dementia. Third, data pertaining to AMT scores were incomplete and this may have resulted in false positive results in some patients. Fourth, the dataset was not sufficient to adjust for all confounders known to influence the development of delirium. Despite these limitations, our study provided useful information to improve our understanding of the incidence and risk factors of delirium in older patients with hip fracture. We contend that our findings are generalisable and could help other hospitals to develop and implement effective strategies to reduce the incidence of delirium and to improve management.

\section{CONCLUSION}

Independent risk factors for developing delirium in older patients with hip fracture were age, dementia, surgical treatment, elevated body temperature, urinary tract infection, and acute coronary syndrome. Delirium was associated with prolonged hospitalisation and increased morbidity and mortality. The structured integrated care programme in our unit enables early recognition of delirium for prevention and management of delirium in older patients with hip fracture and might contribute to better outcomes.

\section{DECLARATION}

The authors have no conflict of interest to disclose.

\section{REFERENCES}

1. United Nations, Department of Economic and Social Affairs, Population Division 2017. World Population Prospects: The 2017 Revision, Data Booklet. ST/ESA/SER.A/401.

2. United Nations, Department of Economic and Social Affairs, Population Division 2017. World Population Ageing 2017, Data booklet ST/ESA/SER.A/408.

3. Kyziridis TC. Post-operative delirium after hip fracture treatment: a review of the current literature. Psychosoc Med 2006;3:Doc01.

4. Mithal A, Bansal B, Kyer CS, Ebeling P. The Asia-Pacific Regional Audit: epidemiology, costs, and burden of osteoporosis in India 2013: a report of the International Osteoporosis Foundation. Indian J Endocrinol Metab 2014;18:449-54. Crossref

5. Chandran M, Howe TS, Goh SK, et al.Vitamin D levels, physical and biochemical characteristics of South East Asian patients with osteoporotic hip fractures. J ASEAN Fed Endocr Soc 2012;27:18590. Crossref

6. Zywiel MG, Hurley RT, Perruccio AV, Hancock-Howard RL, Coyte PC, Rampersaud YR. Health economic implications of perioperative delirium in older patients after surgery for a fragility hip fracture. J Bone Joint Surg Am 2015;97:829-36. Crossref

7. Gupta N, de Jonghe J, Schieveld J, Leonard M, Meagher D. Delirium phenomenology: what can we learn from the symptoms of delirium? J Psychosom Res 2008;65:215-22. Crossref

8. Lee HB, Mears SC, Rosenberg PB, Leoutsakos JM, Gottschalk A, Sieber FE. Predisposing factors for postoperative delirium after hip fracture repair in individuals with and without dementia. J Am Geriatr Soc 2011;59:2306-13. Crossref

9. McCusker J, Cole MG, Dendukuri N, Belzile E. Does delirium increase hospital stay? J Am Geriatr Soc 2003;51:153946. Crossref

10. Olofsson B, Lundstrom M, Borssen B, Nyberg L, Gustafson Y. Delirium is associated with poor rehabilitation outcome in 
elderly patients treated for femoral neck fractures. Scand J Caring Sci 2005;19:119-27. Crossref

11. O'Keeffee ST. Delirium in the elderly. Age Ageing 1999;28(Suppl 2):5-8. Crossref

12. Holmes J, House A. Psychiatric illness predicts poor outcome after surgery for hip fracture: a prospective cohort study. Psychol Med 2000;30:921-9. Crossref

13. Lundstrom M, Edlund A, Bucht G, Karlsson S, Gustafson Y. Dementia after delirium in patients with femoral neck fractures. J Am Geriatr Soc 2003;51:1002-6. Crossref

14. Mosk CA, Mus M, Vroemen JP, et al. Dementia and delirium, the outcomes in elderly hip fracture patients. Clin Interv Aging 2017;12:421-30. Crossref

15. Colon-Emeric CS. Postoperative management of hip fractures: interventions associated with improved outcomes. Bonekey Rep 2012;1:241. Crossref

16. Bellelli G, Mazzola P, Morandi A, et al. Duration of postoperative delirium is an independent predictor of 6-month mortality in older adults after hip fracture. J Am Geriatr Soc 2014;62;133540. Crossref

17. Mitchell R, Harvey L, Brodaty H, Draper B, Close J. One-year mortality after hip fractures in older individuals: the effects of delirium and dementia. Arch Gerontol Geriatr 2017;72:13541. Crossref

18. American Geriatrics Society Expert Panel on Postoperative Delirium in Older Adults. American Geriatrics Society abstracted clinical practice guideline for postoperative delirium in older adults. J Am Geriatr Soc 2015;63:142-50. Crossref

19. Galanakis P, Bickel H, Gradinger R, von Gumppenberg S, Forstl $\mathrm{H}$. Acute confusional state in the elderly following hip surgery: incidence, risk factors and complications. Int J Geriatr Psychiatry 2001;16:349-55. Crossref

20. Duppils GS, Wikblad K. Acute confusional states in patients undergoing hip surgery: a prospective observation study. Gerontology 2000;46:36-43. Crossref

21. Suwanpasu S, Grinslade S, Wu YWB, Porock D. Risk factors of delirium in elderly patients with hip fracture. Asian Biomed 2014;8:157-65. Crossref

22. Edlund A, Lundstrom M, Brannstrom B, Bucht G, Gustafson Y. Delirium before and after operation for femoral neck fracture. J Am Geriatr Soc 2001;49:1335-40. Crossref

23. Morrison RS, Magaziner J, Gilbert M, et al. Relationship between pain and opioid analgesics on the development of delirium following hip fracture. J Gerontol A Biol Sci Med Sci 2003;58:7681. Crossref
24. Zakriya KJ, Christmas C, Wenz JF Sr, Franckowiak S, Andersen $\mathrm{R}$, Sieber FE. Preoperative factors associated with postoperative change in confusion assessment method score in hip fracture patients. Anesth Analg 2002;94:1628-32. Crossref

25. Edlund A, Lundstrom M, Lundstrom G, Hedqvist B, Gustafson Y. Clinical profile of delirium in patients treated for femoral neck fractures. Dement Geriatr Cogn Disord 1999;10:325-9. Crossref

26. Marcantonio ER, Flacker JM, Michaels M, Resnick NM. Delirium is independently associated with poor functional recovery after hip fracture. J Am Geriatr Soc 2000;48:618-24. Crossref

27. Wang LH, Xu DJ, Wei XJ, Chang HT, Xu GH. Electrolyte disorders and aging: risk factors for delirium in patients undergoing orthopedic surgeries. BMC Psychiatry 2016;16:418. Crossref

28. Oh ES, Sieber FE, Leoutsakos JM, Inouye SK, Lee HB. Sex differences in hip fracture surgery: preoperative risk factors for delirium and postoperative outcomes. J Am Geriatr Soc 2016;64:1616-21. Crossref

29. Pinho C, Cruz S, Santos A, Abelha FJ. Postoperative delirium: age and low functional reserve as independent risk factors. J Clin Anesth 2016;33:507-13. Crossref

30. Hirsch J, DePalma G, Tsai TT, Sands LP, Leung JM. Impact of intraoperative hypotension and blood pressure fluctuations on early postoperative delirium after non-cardiac surgery. Br J Anaesth 2015;115:418-26. Crossref

31. Mangusan RF, Hooper V, Denslow SA, Travis L. Outcomes associated with postoperative delirium after cardiac surgery. Am J Crit Care 2015;24:156-63. Crossref

32. Wei LA, Fearing MA, Sternberg EJ, Inouye SK. The Confusion Assessment Method: a systematic review of current usage. J Am Geriatr Soc 2008;56:823-30. Crossref

33. Yang Y, Zhao X, Dong T, Yang Z, Zhang Q, Zhang Y. Risk factors for postoperative delirium following hip fracture repair in elderly patients: a systematic review and meta-analysis. Aging Clin Exp Res 2017;2:115-26. Crossref

34. Wang Y, Tang J, Zhou F, Yang L, Wu J. Comprehensive geriatric care reduces acute perioperative delirium in elderly patients with hip fractures: a meta-analysis. Medicine (Baltimore) 2017;96:e7361. Crossref

35. Bruce AJ, Ritchie CW, Blizard R, Lai R, Raven P. The incidence of delirium associated with orthopedic surgery: a meta-analytic review. Int Psychogeriatr 2007;19:197-214. Crossref

36. Kazmierski J, Banys A, Latek J, et al. Mild cognitive impairment with associated inflammatory and cortisol alterations as independent risk factor for postoperative delirium. Dement Geriatr Cogn Disord 2014;38:65-78. Crossref 